\title{
Effect of Growth Stage on Susceptibility of Grape Berry and Rachis Tissues to Infection by Phomopsis viticola
}

\author{
O. Erincik and L. V. Madden, Department of Plant Pathology, The Ohio State University, Wooster 44691; D. C. \\ Ferree, Department of Horticulture and Crop Science, The Ohio State University; and M. A. Ellis, Department of \\ Plant Pathology, The Ohio State University
}

\begin{abstract}
Erincik, O., Madden, L. V., Ferree, D. C., and Ellis, M. A. 2001. Effect of growth stage on susceptibility of grape berry and rachis tissues to infection by Phomopsis viticola. Plant Dis. 85:517-520.

Intact 'Seyval' grape clusters in the greenhouse and 'Catawba' clusters in the field were inoculated with conidia of Phomopsis viticola at seven Eichorn-Lorenz growth stages between 12 (prebloom) and 35 (véraison) in 1998. Five pots (10 clusters) were used per inoculation, and the experiment was repeated three times. Also, 10 to 20 randomly selected Catawba clusters were inoculated in the field for each of three replications at each growth stage. Studies were repeated in 1999. In addition, Chambourcin clusters were also inoculated at four growth stages in the greenhouse in 1999. Results obtained in the greenhouse and field during both years and for all cultivars indicate that berry and rachis infections can occur at all growth stages between 12 and 35 with no evidence of decreasing susceptibility over time. Results disagree with some literature reports that indicate that berry infection occurs primarily during bloom and shortly after bloom, and susceptibility decreases as fruit matures.
\end{abstract}

Additional keywords: integrated disease management, latent infection

Phomopsis cane and leaf spot, caused by Phomopsis viticola (Sacc.) Sacc., is an important disease of grapes in many viticultural regions worldwide $(2,4,5,13$, 16,17). The incidence of Phomopsis cane and leaf spot has been increasing in Ohio vineyards (7). In 1997, yield losses from Phomopsis disease were estimated at $30 \%$ in several commercial vineyards in Southern Ohio (M. Ellis, unpublished data).

$P$. viticola can infect canes, leaves, the rachis (cluster stem), and berries. Although cane infections can result in some damage and are probably the primary source of inoculum, rachis and berry infections result in the highest yield reductions and economic loss $(12,14,15)$. Aspects of the cane and leaf spot phase of the disease have been studied in some detail $(1,2,13,16,17)$. The fruit rot phase of the disease has also been studied; however, some reports give

Corresponding author: M. A. Ellis E-mail: ellis.7@osu.edu

Salaries and support provided by state and federal funds (especially grants from the Ohio Grape Industries Program and the USDA Viticulture Consortium-East through a subcontract with Cornell University, NYSAES, under agreement \#34360-7382) appropriated to the Ohio Agricultural Research and Development Center, The Ohio State University, Wooster.

Accepted for publication 31 January 2001.

Publication no. D-2001-0312-01R

(C) 2001 The American Phytopathological Society conflicting results. The fruit rot phase was first described by Gregory (9), who reported that brown necrotic lesions with numerous pycnidia developed on infected berries. Eventually the entire berry was diseased and shriveled into a mummy. Gregory (9) determined that ripe Vitis labrusca 'Niagra' fruit showed symptoms within 18 days after inoculation, indicating that ripe fruit are susceptible. Lal and Arya (10) reported that ripe $V$. vinifera 'Thompson Seedless' berries could not be infected unless they were wounded prior to inoculation. Pscheidt and Pearson (15) reported that $V$. labrusca. 'Concord' berries were susceptible to infection by $P$. viticola during and shortly after bloom, with little or no infection occurring later in the growing season. They further reported that early season berry infections remain latent in green fruit until close to harvest, when they become active and fruit rot symptoms develop (15). They also reported that the rachis is susceptible to infection from bud break through bloom, with no mention of rachis susceptibility later in the growing season (15). Based largely on this report, fungicides for control of berry and rachis infections are currently applied prebloom through shortly after bloom (8).

Several growers in Ohio have obtained poor control of rachis and berry infection even after applying fungicide from prebloom to postbloom (M. Ellis, unpublished data). Based on field observations and grower experiences, the period of grape berry and rachis infection needs to be more clearly defined. The objective of this study was to determine the time of grape berry and rachis susceptibility to infection by $P$. viticola.

\section{MATERIALS AND METHODS}

Greenhouse studies; preparation of plants with intact clusters. Greenhouse studies were conducted in 1998 and 1999. Potted plants of 'Seyval' with intact clusters were produced. Bare rooted cuttings were planted in a mixture of peat, steam disinfected loam, and perlite (1:1:1, $\mathrm{vol} / \mathrm{vol}$ ) in 20-cm plastic pots in May 1997. Plants were trained to a single shoot and allowed to grow outside until they became dormant in November. Dormant plants were placed in cold storage $\left(0^{\circ} \mathrm{C}\right)$ until March 1998, when they were placed in the greenhouse. Shortly after bud break, vines were cut to a height of approximately 50 $\mathrm{cm}$. Two buds with fruit clusters were selected and each plant trained to two shoots with one cluster per shoot. Plants were fertilized with $18 \mathrm{~g}$ of osmocote (14-14-14 N-P-K) every other month and were watered as needed with deionized water, taking care not to wet flowers or fruit clusters. These procedures were repeated in 1998 for plants to be used in 1999 .

Preparation of inoculum. Fifteen isolates of $P$. viticola were collected from infected grape vines in five commercial Ohio vineyards in 1997. Inoculations were conducted to confirm pathogenicity of all isolates on grape. In addition, conidia and mycelium morphology of all isolates were compared to a known isolate of $P$. viticola obtained from M. E. Palm, USDA/APHIS, Beltsville, MD. Representative isolates were sent to M. E. Palm and were confirmed to be $P$. viticola. Whereas all isolates were pathogenic and produced typical symptoms on grape, the isolate obtained from M. E. Palm was consistently the most aggressive in preliminary studies and was chosen for use in this study. Pathogenicity of the isolate was maintained by inoculating surface-disinfested disks cut from mature grape berries ('Thompson Seedless') placed on potato-dextrose agar (PDA; 3). Plugs cut from the edge of actively growing mycelia were placed in the center of each disk, and the pathogen was reisolated from the PDA after it had grown through the disk. Cultures were grown on PDA in petri plates at $21^{\circ} \mathrm{C}$ under continuous fluorescent light at $58 \mu \mathrm{E} \mathrm{m} \mathrm{m}^{-2} \mathrm{~s}^{-1}$ for 15 to 20 
days. Conidia were collected by flooding culture plates with sterile deionized water (3). Pycnidia and conidia were detached by rubbing the surface with a paint brush. The suspension was filtered through four layers of cheesecloth, and adjusted to $1 \times 10^{7}$ conidia (alpha spores) per milliliter using a hemacytometer.

Inoculation of clusters. The conidial suspension was sprayed to runoff onto attached clusters at various stages of development. Noninoculated control plants were sprayed with water only. Developmental growth stages were determined using the Eichorn-Lorenz growth stage scale (6; Table 1). Inoculations were performed at Eichorn-Lorenz stages 12 (prebloom), 17, 23, 27, 29, 33, and 35 (véraison). For each growth stage, 10 clusters (from five pots) were inoculated. The experiment was conducted three times, with each experiment considered a replication. Inoculated and noninoculated plants with attached clusters were placed in a moist chamber immediately after inoculation in order to maintain continuous wetness at $20^{\circ} \mathrm{C}$ for $24 \mathrm{~h}$. Plants then were returned to the greenhouse and observed daily. The presence of symptoms on fruit and rachises was recorded.

Fruit rot symptoms were assessed as fruit matured up to harvest. Individual berries were harvested daily as rot symptoms developed. The number of fruit was

Table 1. Eichorn-Lorenz growth stages used for cluster inoculations ${ }^{2}$

\begin{tabular}{ll}
\hline Stage & \multicolumn{1}{c}{ Description } \\
\hline 12 & Five to six leaves unfolded, inflorescence clearly visible ( "prebloom") \\
17 & Inflorescence fully developed, flowers separating \\
23 & Full flowering, 50\% of caps fallen ("bloom") \\
27 & Fruit set, young fruit beginning to swell, remains of flowers lost \\
29 & Berries small; bunches begin to hang \\
31 & Berries pea-sized; bunches hang \\
33 & Beginning of berry touch \\
35 & Beginning of berry ripening (véraison) \\
\hline
\end{tabular}

${ }^{\mathrm{z}}$ See pages 3-7 in Pearson and Gohen (12) for more details and diagrams.

Table 2. Mean Phomopsis fruit rot incidence and disease severity on rachises from intact 'Seyval' clusters inoculated at various growth stages in greenhouse studies in $1998^{\mathrm{w}}$

\begin{tabular}{lcc}
\hline Growth stage $^{\mathbf{x}}$ & ${\text { Fruit rot incidence }(\%)^{\mathbf{y}}}$ & ${\text { Disease severity on rachis }(\%)^{\mathbf{z}}}^{\text {Control }}$ \\
12 & $0.0 \mathrm{~d}$ & $0.0 \mathrm{~d}$ \\
17 & $53.8 \mathrm{ac}$ & $74.6 \mathrm{a}$ \\
23 & $46.2 \mathrm{c}$ & $50.0 \mathrm{~b}$ \\
27 & $67.4 \mathrm{abc}$ & $54.7 \mathrm{~b}$ \\
29 & $68.9 \mathrm{ab}$ & $61.7 \mathrm{a}$ \\
33 & $65.7 \mathrm{abc}$ & $57.9 \mathrm{~b}$ \\
35 & $74.5 \mathrm{a}$ & $73.9 \mathrm{a}$ \\
\hline
\end{tabular}

${ }^{\text {w}}$ Means followed by different letters within a column are significantly different $(P=0.05)$ based on Fisher's least significant difference, calculated based on arcsine square-root transformed percentage data. Only the untransformed mean percentages are shown.

${ }^{\mathrm{x}}$ Growth stages were selected based on the Eichhorn-Lorenz growth stage scale (12).

y Mean percentage of Phomopsis fruit rot based on the number of rotted fruit from 10 clusters per each of three replications for each growth stage.

${ }^{\mathrm{z}}$ Mean disease severity on rachises based on ratings from 10 clusters per each of three replications for each growth stage.

Table 3. Mean Phomopsis fruit rot incidence and disease severity on rachises from intact 'Seyval' clusters inoculated at various growth stages in greenhouse studies in $1999^{\mathrm{w}}$

\begin{tabular}{lcc}
\hline Growth stage $^{\mathbf{x}}$ & ${\text { Fruit rot incidence }(\%)^{\mathbf{y}}}$ & ${\text { Disease severity on rachis }(\%)^{\mathbf{z}}}^{\text {Control }}$ \\
12 & $0.0 \mathrm{e}$ & $0.0 \mathrm{~d}$ \\
17 & $64.4 \mathrm{~d}$ & $30.5 \mathrm{bc}$ \\
23 & $81.4 \mathrm{bc}$ & $57.4 \mathrm{a}$ \\
27 & $88.7 \mathrm{ab}$ & $58.6 \mathrm{a}$ \\
29 & $83.9 \mathrm{~b}$ & $60.5 \mathrm{a}$ \\
33 & $86.4 \mathrm{ab}$ & $43.1 \mathrm{ab}$ \\
35 & $91.9 \mathrm{a}$ & $57.2 \mathrm{a}$ \\
\hline
\end{tabular}

${ }^{\text {w}}$ Means followed by different letters within a column are significantly different $(P=0.05)$ based on Fisher's least significant difference, calculated based on arcsine square-root transformed percentage data. Only the untransformed mean percentages are shown.

${ }^{x}$ Growth stages were selected based on the Eichhorn-Lorenz growth stage scale (12).

${ }^{y}$ Mean percentage of Phomopsis fruit rot based on the number of rotted fruit from 10 clusters per each of three replications for each growth stage.

${ }^{\mathrm{z}}$ Mean disease severity on rachises based on ratings from 10 clusters per each of three replications for each growth stage. recorded and the percentage of rotted fruit (incidence) was calculated. The experiment was terminated and all clusters harvested when remaining berries reached a mean of $21 \%$ sugar content. Sugar content was determined using a composite sample of 10 berries in greenhouse and 25 berries in field studies. Juice was squeezed from the berries and sugar content measured using a refractometer. Apparently healthy berries from uninoculated controls were used and were recorded as healthy berries. Disease severity on rachises was recorded at harvest using the Horsfall-Barratt scale for assessment.

The experiment was repeated in 1999 with the addition that intact clusters of 'Chambourcin' were inoculated in the greenhouse at growth stages 17, 23, 31, and 35.

Field studies. In 1998, field studies were conducted in a 4-year-old Catawba vineyard at the Ohio Agricultural Research and Development Center (OARDC), Wooster. Randomly selected clusters (10 to 20) at each growth stage were inoculated as previously described. Noninoculated clusters served as controls. In addition to the seven growth stages inoculated in the greenhouse, growth stage 31 (Table 1) was also inoculated in the field. Inoculations were started at growth stage 12 on 14 May, and continued at growth stages 17, 23, 29, 31, 33 , and 35 on 23 May, 29 May, 7 June, 16 June, 21 June, 28 June, and 9 September, respectively. To maintain surface wetness, plants were overhead irrigated by a misting system for $24 \mathrm{~h}$ after inoculation. Temperature, relative humidity, and wetness duration in the vineyard were recorded regularly by a Campbell Scientific Data Logger (Model CR21; Logan, Utah). There were three replications of 10 to 20 clusters each per growth stage in a completely randomized design.

Assessment of disease incidence was initiated on 26 August as symptoms on berries developed near harvest as described for greenhouse studies. Infected berries were harvested at 3-day intervals through harvest. The experiment was terminated and all clusters were harvested when the berries reached a mean of $21 \%$ sugar content on 21 September. Percentage of infected berries (incidence) was calculated for each growth stage.

Field experiments were repeated in 1999. Inoculations started at growth stage 12 on 17 May, and continued at stages 17 , $23,27,29,31,33$, and 35 on 20 May, 5 June, 9 June, 23 June, 33 July, and 1 September, respectively. Assessment of fruit rot incidence was initiated near harvest on 8 September, and continued until harvest on 30 September. In both 1998 and 1999, disease severity on rachises were assessed at harvest as previously described.

Data analysis. Data were analyzed with analysis of variance (ANOVA) using the GLM command of the Minitab statistical 
package (11). Experimental factors were growth stage and replication (block). Individual clusters or rachises were treated as subsamples. The arcsine square root transformations of the proportion of fruit rot incidence and disease severity on rachises were used for the GLM procedure. Means were separated using Fisher's least significant difference (LSD; $P=0.05$ ) if the $F$ test for growth stage indicated a significant effect. We did not hypothesize any particular continuous functional relationship between disease and growth stage; therefore, orthogonal polynomials were not used.

\section{RESULTS AND DISCUSSION}

Greenhouse inoculations at all growth stages of Seyval and Chambourcin clusters resulted in some level of fruit rot (Tables 2, 3 , and 4). No fruit rot developed on any of the uninoculated controls. Although the observed incidence of fruit rot increased from $54 \%$ at prebloom (stage 12 ) to $75 \%$ at berry touch (stage 33 ) in 1998, there were no significant differences $(P=0.05)$ between these growth stages in fruit rot incidence (Table 2).

In 1999, results for both Seyval and Chambourcin inoculations were very similar to those obtained in 1998 (Tables 2, 3 , and 4). At growth stage 33, fruit rot incidence was significantly higher (92\%) than at growth stages $12,17,27$, and 35 on Seyval. There were no significant differences between growth stages 17, 23, 27, and 29 in fruit rot incidence (Table 3). These results indicate that berries remain susceptible to infection throughout the growing season. Results for both years differ from those of Pscheidt and Pearson (15), who reported that berry infections on 'Concord' occur primarily during bloom and shortly after bloom, and that susceptibility decreased as fruit matured. Gregory (9) reported that ripe berries of 'Niagra' developed fruit rot 18 days after inoculation, indicating that ripe fruit are susceptible to infection. Results of this study clearly demonstrated that berries are susceptible to infection throughout the growing season (Tables 2, 3, and 4). Our results agree with those of Pscheidt and Pearson, that fruit infection can occur very early in the growing season (prebloom, stage 12) and that the infections remain latent until berries begin to ripen. Fruit rot was rarely observed on green fruit in our studies. Although fruit rot incidence was significantly lower at stage 35 (beginning of berry ripening) than at stage 33 (beginning of berry touch), we speculate that the differences were due to a short incubation period prior to harvest, not to decreased susceptibility.

Cluster inoculations also resulted in rachis infection at all growth stages for both Seyval and Chambourcin (Tables 2, 3, and 4). No rachis infection was observed on noninoculated controls. In 1998, growth stages $12(75 \%)$ and $33(74 \%)$ had signifi- cantly greater disease severity $(P=0.05)$ than all other growth stages (with the exception of growth stage 35). There were no significant differences between growth stages 17 through 29 (Table 2). As with fruit rot incidence, disease severity on rachises significantly decreased from growth stage $33(74 \%)$ to growth stage 35 $(30 \%)$. Again, we speculate that the decrease was not due to reduced susceptibility but to the short incubation period from inoculation to harvest. Greenhouse results from 1999 were very similar to those of 1998; however, on Seyval, growth stage 12 had significantly less disease severity than stages 17 through 33, and was not significantly different from stage 35 .

Unlike berry infections that remain latent in green fruit until close to harvest, rachis infections developed within 3 to 4 weeks after inoculation. Pscheidt and Pearson (15) reported that rachis lesions devel-

Table 4. Mean Phomopsis fruit rot incidence and disease severity on rachises from intact 'Chambourcin' clusters inoculated at various growth stages in greenhouse studies in 1999 ${ }^{\mathrm{w}}$

\begin{tabular}{lcc}
\hline Growth stage $^{\mathbf{x}}$ & ${\text { Fruit rot incidence }(\%)^{\mathbf{y}}}$ & ${\text { Disease severity on rachis }(\%)^{\mathbf{z}}}^{\text {Control }}$ \\
17 & $0.0 \mathrm{c}$ & $0.0 \mathrm{f}$ \\
23 & $76.0 \mathrm{ab}$ & $57.6 \mathrm{~b}$ \\
31 & $86.7 \mathrm{a}$ & $62.9 \mathrm{ab}$ \\
35 & $85.9 \mathrm{a}$ & $72.4 \mathrm{a}$ \\
\hline
\end{tabular}

${ }^{\mathrm{w}}$ Means followed by different letters within a column are significantly different $(P=0.05)$ based on Fisher's least significant difference, calculated based on arcsine square-root transformed percentage data. Only the untransformed mean percentages are shown.

${ }^{x}$ Growth stages were selected based on the Eichhorn-Lorenz growth stage scale (12).

${ }^{y}$ Mean percentage of Phomopsis fruit rot based on the number of rotted fruit from 10 clusters per each of three replications for each growth stage.

${ }^{\mathrm{z}}$ Mean disease severity on rachises based on ratings from 10 clusters per each of three replications for each growth stage.

Table 5. Mean Phomopsis fruit rot incidence and disease severity on rachises from intact 'Catawba' clusters inoculated at various growth stages in the field in $1998^{\mathrm{w}}$

\begin{tabular}{lcc}
\hline Growth stage $^{\mathbf{x}}$ & Fruit rot incidence (\%) & ${\text { Disease severity on rachis }(\%)^{\mathbf{z}}}^{\mathbf{y}}$ \\
\hline Control & $10.2 \mathrm{~b}$ & $4.7 \mathrm{c}$ \\
12 & $18.1 \mathrm{~b}$ & $6.5 \mathrm{c}$ \\
17 & $14.3 \mathrm{~b}$ & $5.6 \mathrm{c}$ \\
23 & $31.8 \mathrm{ab}$ & $17.4 \mathrm{c}$ \\
27 & $25.7 \mathrm{~b}$ & $14.6 \mathrm{c}$ \\
29 & $29.9 \mathrm{~b}$ & $18.8 \mathrm{bc}$ \\
31 & $62.9 \mathrm{a}$ & $34.8 \mathrm{ab}$ \\
33 & $58.2 \mathrm{a}$ & $47.3 \mathrm{a}$ \\
35 & $22.4 \mathrm{~b}$ & $8.7 \mathrm{c}$ \\
\hline
\end{tabular}

${ }^{\text {w }}$ Means followed by different letters within a column are significantly different $(P=0.05)$ based on Fisher's least significant difference, calculated based on arcsine square-root transformed percentage data. Only the untransformed mean percentages are shown.

${ }^{x}$ Growth stages were selected based on the Eichhorn-Lorenz growth stage scale (12).

${ }^{\mathrm{y}}$ Mean percentage of Phomopsis fruit rot based on the number of rotted fruit from 10 to 20 clusters per each of three replications for each growth stage.

${ }^{\mathrm{z}}$ Mean percentage disease severity on rachises based on ratings from 10 to 20 clusters per each of three replications for each growth stage.

Table 6. Mean Phomopsis fruit rot incidence and disease severity on rachises from intact 'Catawba' clusters inoculated at various growth stages in the field in $1999^{\mathrm{w}}$

\begin{tabular}{lcc}
\hline Growth stage $^{\mathbf{x}}$ & ${\text { Fruit rot incidence }(\%)^{\mathbf{y}}}$ & ${\text { Disease severity on rachis }(\%)^{\mathbf{z}}}^{\text {Control }}$ \\
12 & $22.8 \mathrm{~d}$ & $4.6 \mathrm{f}$ \\
17 & $56.1 \mathrm{c}$ & $23.8 \mathrm{de}$ \\
23 & $60.3 \mathrm{c}$ & $14.6 \mathrm{e}$ \\
27 & $83.8 \mathrm{a}$ & $31.1 \mathrm{~cd}$ \\
29 & $59.6 \mathrm{c}$ & $14.2 \mathrm{e}$ \\
31 & $74.4 \mathrm{~b}$ & $33.4 \mathrm{c}$ \\
33 & $88.7 \mathrm{a}$ & $66.7 \mathrm{a}$ \\
35 & $85.5 \mathrm{a}$ & $54.9 \mathrm{~b}$ \\
\hline
\end{tabular}

${ }^{\text {w}}$ Means followed by different letters within a column are significantly different $(P=0.05)$ based on Fisher's least significant difference, calculated based on arcsine square-root transformed percentage data. Only the untransformed mean percentages are shown.

${ }^{x}$ Growth stages were selected based on the Eichhorn-Lorenz growth stage scale (12).

${ }^{y}$ Mean percentage of Phomopsis fruit rot based on the number of rotted fruit from 10 to 20 clusters per each of three replications for each growth stage.

${ }^{\mathrm{z}}$ Mean percentage disease severity on rachises based on ratings from 10 to 20 clusters per each of three replications for each growth stage. 
oped after inoculation at $12.7-\mathrm{cm}$ shoot growth or at bloom, and that rachises were susceptible to infection from bud break through bloom. They make no mention of rachis susceptibility later in the growing season. Our data suggest that rachis tissues are susceptible to infection throughout the growing season (Tables 2, 3, and 4). Pscheidt and Pearson further reported that rachis infections develop into brittle lesions that can cause the entire cluster or portions of the cluster to fall from the vine before harvest (15). Therefore, they concluded that rachis infection is the most important phase of this disease. Although we did not observe this type of berry drop in this study, it is commonly observed in vineyards when natural epidemics occur in Ohio (M. Ellis, unpublished data), and we concur that rachis infection is a very important phase of this disease.

Results from field studies were similar to those obtained from greenhouse experiments (Tables 5 and 6). Unlike the greenhouse studies, fruit rot and rachis infections were observed on noninoculated controls due to natural infection in the vineyard. In 1998, inoculation at growth stages 31 and 33 had significantly higher fruit rot incidences, and growth stages 29 , 31 , and 33 had significantly higher rachis disease severity than the noninoculated control (Table 5). There were no significant differences in disease among the other stages. In 1999, all growth stages had significantly higher fruit rot incidence and rachis disease severity than the noninoculated control (Table 6). In general, disease susceptibility appeared to increase at growth stages 31 and 33. It is interesting to note that the noninoculated control had $23 \%$ fruit rot from natural infection in 1999. This further documents the economic importance of this disease.

In summary, the results of this study suggest that grape berry and rachis tissues are susceptible to infection by $P$. viticola throughout the growing season. The reasons for the differences between our results and those reported by Pscheidt and Pearson (15) are not clear. Their results were from field studies using the cultivar Concord and inoculations at prebloom, bloom, postbloom, and véraison. Our studies were conducted on greenhouse and field grown plants using, in total, three cultivars and eight growth stages (two prebloom, bloom, four postbloom, and véraison). Although differences in varietal susceptibility could partially explain the differences in results, information on variation in varietal susceptibility has not been reported, and we have not observed any apparent differences in Ohio vineyards. Typical symptoms of Phomopsis cane and leaf spot (including rachis infections and fruit rot) are commonly observed in the field on all cultivars used in these studies as well as on Concord. Variation in the pathogen could also be partially responsible for differences in results. In this study, several isolates were collected from five vineyards in 1997. All isolates were compared to a known isolate of $P$. viticola and all produced typical symptoms of cane and leaf spot in pathogenicity tests. At least three of the isolates were obtained from Concord. Symptoms observed on all cultivars in this study were identical to those observed in the field on numerous cultivars, including Concord. We have no evidence to support the idea that pathogen variation can account for differences observed in these studies.

The significance of late-season berry and rachis infections under natural field conditions cannot be determined from these studies alone. Although we have demonstrated that tissues remain susceptible, the level of late-season infection under natural conditions is not known. For cane (internodes) and leaf infections, symptoms often are observed only on the first through the third or fourth internode or leaf (M. Ellis, unpublished data). Symptoms are rarely observed on plant parts that develop later in the season. This supports the importance of early season infection and the need for early season disease control. If late-season infections do not occur, this could be due to factors such as depletion of primary inoculum or unfavorable weather conditions for infection (e.g., temperaturewetness combinations) later in the growing season. Nevertheless, failure to obtain adequate control of Phomopsis fruit rot in some vineyards with only early season fungicide applications (M. Ellis, unpublished data) suggests that infections later in the growing season are possible. Further studies need to be conducted to determine the magnitude of late-season (postbloom) berry and rachis infection and the possible need to adjust fungicide programs to provide additional disease control.

\section{LITERATURE CITED}

1. Arya, A., and Lal, B. 1986. Biochemical changes in grapes infected with Phomopsis viticola. J. Plant Sci. Res. 2:53-59.

2. Bugaret, Y. 1984. L'Excoriose de la vigne: Recherches sur le Phomopsis viticola Sacc., nouvelles possibilities de lutte. Ph.D. thesis. University of Bordeaux, France.

3. Bulger, M., Ellis, M. A., and Madden, L. V. 1987. Influence of temperature and wetness duration on infection of strawberry flowers by Botrytis cinerea and disease incidence of fruit originating from infected flowers. Phytopathology 77:1225-1230.

4. Bulit, J., Bugaret, Y., and Lafon, R. 1972. L'Excoriose de la vigne et ses traitements. Rev. Zool. Agric. Pathol. Veg. 71:44-54.

5. Cucuzza, J. D., and Sall, M. A. 1982. Phomopsis cane and leaf spot disease of grapevine: Effects of chemical treatments on inoculum level, disease severity and yield. Plant Dis. 66:794-797.

6. Eichorn, K. W., and Lorenz, D. H. 1977. Phänologishche Enwicklungsstadien der Rebe. Nachrbl. Dtsch. Pflanzenschutzd. (Braunschweig) 29:119-120.

7. Ellis, M. A. 1999. Understanding and controlling Powdery mildew and Phomopsis cane and leaf spot of grape. Pages 73-81 in: Proc. 1998 Ohio Grape-Wine Short Course. Hortic Dep. Ser. 682. OARDC, Wooster, OH

8. Funt, R. C., Ellis, M. A., and Welty, C. 1997. Midwest Small Fruit Pest Management Handbook. The Ohio State Univ. Bull. 861.

9. Gregory, C. T.1913. A rot of grapes caused by Cryptosporella viticola. Phytopathology 3:20-23.

10. Lal, B, and Arya, A. 1982. A soft rot of grape caused by Phomopsis viticola. Indian Phytopathol. 35(2):261-264.

11. Minitab User's Guide Statistics. 1998. Version 12 ed. Minitab Inc. State College, PA.

12. Pearson C. R., and Goheen C. A. 1990. Compendium of Grape Disease. American Phytopathological Society Press, St. Paul, MN.

13. Pine, T. S. 1959. Development of the grape dead-arm disease. Phytopathology 49:738-743.

14. Pscheidt, J. W., and Pearson, R. C. 1989. Effect of grapevine training systems and pruning practices on occurrence of Phomopsis cane and leaf spot. Plant Dis. 73:825-828.

15. Pscheidt, J. W., and Pearson, R. C. 1989. Time of infection and control of Phomopsis fruit rot of grape. Plant Dis. 73:829-833.

16. Reddick, D. 1914. Dead-arm disease of grapes. Pages 463-490 in: N.Y. Agric. Exp. Stn. Bull. 389.

17. Willison, R. S., Chamberlain, G. C., Townsend, J. L., and de Ronde, J. H. 1965. Epidemiology and control of dead-arm of grapes. Can. J. Bot. 43:901-914. 